\title{
Is the novel suspension exercises superior to core stability exercises on some EMG coordinates, pain and range of motion of patients with disk herniation?
}

\author{
Yasser Mohebbi $\operatorname{Rad}^{1} \cdot$ Mohammad Reza Fadaei Chafy $^{1}$ (D) $\cdot$ Alireza Elmieh $^{1}$
}

Received: 7 July 2021 / Accepted: 23 September 2021 / Published online: 20 October 2021

(c) The Author(s), under exclusive licence to Springer-Verlag Italia S.r.l., part of Springer Nature 2021

\begin{abstract}
Information about comparing the effectiveness of exercise methods on management of disk herniation is limited. The aim of this study was to compare the effect of two programs of suspension and core stability exercises on some electromyography (EMG) coordinates, pain and range of motion of patients with disk herniation. Thirty-two men with disk herniation participated in this clinical trial study which was randomly divided into three groups of suspension exercises $(n: 12$, age: $34.25 \pm 8.81$, BMI: $24.01 \pm 2.7$ ), core stability exercises ( $n: 10$, age: $35 \pm 10.3$, BMI: $25 \pm 2.27)$ and control ( $n$ : 10 , age: $34.4 \pm 6.67$, BMI: $23.76 \pm 1.45$ ). Electrical activity of rectus abdominis, internal and external oblique and erector spinae muscles was masured by superficial EMG, back pain by McGill Pain Questionnaire and range of motion by Modified Schober test, one day before and immediately after of intervention period. The experimental groups performed an 8-week training period while the control group was only followed up. Data were analyzed using paired sample $t$ test and analysis of covariance test and statistical significance was set at 0.05 . Suspension group showed significant improvement in EMG of rectus abdominis, internal and external oblique muscles (respectively, $p=0.030, p=0.017, p=0.022)$ and pain $(p=0.001)$ compared to core stability group; but there was no significant difference between two groups in EMG of erector spinae muscle and range of motion. Changes in both training groups were significant in all variables compared to control groups $\left(p^{<} 0.05\right)$. Our findings showed that although both exercises were effective in patients with lumbar disk herniation, but the effectiveness of suspension exercises in increasing muscle activation and reducing pain was more pronounced than core stability exercises. Iranian Registry of Clinical Trials (IRCT): IRCT20191016045136N1.
\end{abstract}

Keywords Suspension exercise $\cdot$ Core stability $\cdot$ Electromyography $\cdot$ Disk herniation

\section{Introduction}

Disk herniation can be defined as displacement of disk material beyond the margins of the intervertebral disk space [1] It is considered the most frequent cause of lumbosacral radiculopathy [2]. Lumbar disk herniation affects about $39 \%$ of chronic low back pain (LBP) patients [3]. Pain is caused by herniated disk pressure on nerve roots and the spinal cord in patient with disk herniation and causes failure or weakness of muscles around spine [4]. The most effective muscles

Mohammad Reza Fadaei Chafy

mfadaei2000@yahoo.com

1 Department of Physical Education and Sport Science, Faculty of Humanities, Rasht Branch, Islamic Azad University, Rasht, Iran involved in trunk stability include multifidus, erector espinae (ES), rectus abdominis (RA), internal oblique (IO), external oblique (EO) and transverse abdominis (TA) [5-7]. Research shows that the electrical activity of these muscles is reduced by LBP $[8,9]$. Also, pain and decrease in normal spine function lead to reduced lumbar range of motion (ROM) [10].

Core stability exercise is one of the most commonly used rehabilitation strategies for improving dynamic stability of the lumbar spine in people with chronic LBP [11]. Core stability refers to an effective recruitment of core muscles (including the abdominal, back, pelvic and hip muscles) leading to an optimal production of force and precise control of lumbopelvic-hip movement, as well as appropriate load transfer from the spine to the pelvis and distal segment. As such, it is thought to be a determinant factor for effective motor performance [12]. Past research has been shown that 
core stability exercise is effective on pain [13], ROM [14] and core muscle activation [15].

In recent years, the addition of instability to traditional exercises has become a popular method for increasing benefit of sport such as suspension exercises. Suspension exercise is defined as having one or more straps connected to one or more anchor point(s) as the user is suspended from the handles of the straps by either their hands or feet, while the nonsuspended pair of extremities is in contact with the ground [16]. An unstable resistance training environment stresses the neuromuscular system and may promote greater strength gains [17]. Unstable training may also increase motor unit recruitment and improve neuromuscular coordination without an increase in the mechanical load when performing the movement under unstable condition [18]. According to high consistency between nervous system efficiency and muscle strength with LBP [4], suspension exesrcise may be particularly useful for rehabilitation and pain of patients with chronic LBP [19-21]. Recent research supports the use of suspensions in muscle activation [22-24], but there are conflicting opinions in comparison between suspension and core stability exercises [23, 25]. The effect of these exercises on ROM is also mentioned differently [14, 26, 27]. Among the wide variety of suspension exercises, the most appropriate posture for people with chronic LBP has not been determined yet. Also, there is limited information about efficacy of this method in patients with disk herniation and comparison of these two exercises method in improving pain and ROM. Therefore, the aim of the present study was to compare the effect of core stability and suspension exercises on some EMG coordinates, pain and ROM in patients with lumbar disk herniation. It was hypothesized that suspension exercise is more effective than core stability exercises.

\section{Methods}

The present study was a clinical trial and the subjects included male volunteers who referred to the physiotherapy clinic in Rasht City of Iran after invitation for six months and data conducted from September to November 2020.

\section{Participants}

Posterior lateral disk herniation in the lumbar vertebrae with grade 1 (bulge) and 2 (protrusion) in subjects was confirmed by a neurosurgeon with magnetic resonance imaging (MRI). Other inclusion criteria included a history of LBP for more than three months, not having specific diseases, not participating in regular exercises and not using other treatments for LBP during the intervention. Written consent was obtained from the individuals. Other ethical considerations included confidentiality and confidentiality for individual participants, complete freedom to withdraw from research and information about research. First, 82 people were selected by convenience sampling and $\mathrm{G}^{*}$ Power software version 3.1 with an analytical power of 0.8 and effect size of 0.5 with a $95 \%$ confidence interval, was used to determine the sample size $[28,29]$. Based on this, a sample of 42 people was suggested that due to possibility of falling research samples, 45 people were selected by purposive sampling after reviewing the inclusion criteria. Until the beginning of the study, 9 people withdrew due to corona pandemic.

\section{Study design}

Subjects were randomly divided into 3 groups of 12 people including suspension exercises, core stability exercises and control group by simple randomization (envelop shuffling). 2 people from core stability exercises and 2 people from control group could not complete the course and were excluded from the study. Anthropometric measurements (including height with bar meter, weight with german BEURER digital balance and body mass index calculated from weight by kilograms divided per square height by meter) and tests related to EMG data, pain and ROM were performed one day before and immediately after the intervention period. Pain and ROM test were taken from 6 to $7 \mathrm{pm}$ and EMG from 8 to $10 \mathrm{pm}$ in both pre- and post-test. The intervention period was 8 weeks and 3 sessions per week in pranic sport club in Rasht City. Each exercise session consisted of three parts: warm-up (10 min), exercise (30-40 min) and cool down (5 min). Researchers asked participants to report any increase in pain during the intervention period. It should be noted all three groups (experimental and control groups) performed several self-care methods at home during the study and no intervention was performed on control group.

\section{Experimental groups intervention}

Core stability group exercises included bridging, push-up, plank, oblique sit-up, thigh abduction, thigh flexion, warp leg in abdomen and lifting pelvic in side lying (Table 1). In the first session, plank exercise was performed 1 repetition with $5 \mathrm{~s}$ hold and other exercises performed 4 repetitions ( $1 \mathrm{~min}$ rest was considered between repetitions) and there was a 2-min break between each exercise and the next exercise. Exercises repetitions increased to 6 repetitions in the third and fourth weeks ( 1 repetition with $8 \mathrm{~s}$ hold for Plank), 8 repetitions in the fifth and sixth weeks (1 repetition with $11 \mathrm{~s}$ hold for Plank) and 10 repetitions in the seventh and eighth weeks (1 repetition with $15 \mathrm{~s}$ hold for Plank). Suspension group exercises were selected with a similar movement pattern included suspension bridging, push-up, plank, oblique leg fold, thigh abduction, thigh flexion, warp leg in abdomen, bring leg left and 
Table 1 How to perform core stability and suspension exercise

\begin{tabular}{|c|c|c|}
\hline \multicolumn{2}{|l|}{ Exs } & \multirow{2}{*}{$\begin{array}{l}\text { How to performed } \\
\text { Lie supine and place the ankles on a pillow. Then, lift the hips off the } \\
\text { ground by contracting the back and thigh muscles }\end{array}$} \\
\hline Core stability exercise & Bridging & \\
\hline & Push-up & $\begin{array}{l}\text { Lie prone with place the hands next to the body and set the elbows and } \\
\text { shoulders on the bent mode. Then lift the trunk from ground by exten- } \\
\text { sion the elbow so that only the palms and soles of the feet are on ground }\end{array}$ \\
\hline & Plank & $\begin{array}{l}\text { Lie prone with place the hands next to the body and set the elbows and } \\
\text { shoulders on the bent mode. Then lift the trunk off ground so that only } \\
\text { the forearms and toes are on ground }\end{array}$ \\
\hline & Oblique sit-up & $\begin{array}{l}\text { Lie supine with the knee bent, then try to bend the trunk with the right } \\
\text { rotation. Repeat this rotation with left side }\end{array}$ \\
\hline & Thigh abduction & $\begin{array}{l}\text { Lie on right side, then abduct your left leg. Repeat this with the opposite } \\
\text { side }\end{array}$ \\
\hline & Thigh flexion & Lie supine, then flex both hips with a straight knee \\
\hline & Wrap legs in abdomen & Lie supine, then flex both legs at the hip and knees \\
\hline & Lifting pelvic in side lying & $\begin{array}{l}\text { Lying on the right side while weight bearing on the forearm. Then lift the } \\
\text { pelvis off ground. Repeat the same with the opposite side }\end{array}$ \\
\hline \multirow[t]{8}{*}{ Suspension exercise } & Suspension bridging & $\begin{array}{l}\text { Lie supine and place the ankles on handle of TRX system. Then, lift the } \\
\text { hips off ground by contracting the back and thigh muscles }\end{array}$ \\
\hline & Suspension push-up & $\begin{array}{l}\text { Lie prone with place the hands next to the body and set the elbows and } \\
\text { shoulders on the bent mode. place the ankles on handle of TRX system. } \\
\text { Then lift the trunk from ground by extension the elbow so that only the } \\
\text { palms are on ground }\end{array}$ \\
\hline & Suspension plank & $\begin{array}{l}\text { Lie prone with place the hands next to the body and set the elbows and } \\
\text { shoulders on the bent mode. place the ankles on handle of TRX system. } \\
\text { Then lift the trunk off ground so that only the forearms are on ground }\end{array}$ \\
\hline & Suspension oblique lef fold & $\begin{array}{l}\text { Hanging from the horizontal bar, then flex both legs from the pelvis and } \\
\text { knees and turned to the right at the same time. Repeat this rotation with } \\
\text { the left side }\end{array}$ \\
\hline & Suspension thigh abduction & $\begin{array}{l}\text { Hanging from the horizontal bar, then abduct the left leg. Repeat with the } \\
\text { right foot }\end{array}$ \\
\hline & Suspension thigh flexion & Hang from the horizontal bar, then flex both thighs with a straight knee \\
\hline & Suspension warp legs in abdomen & Hang from the horizontal bar, then flex both legs at the hip and knees \\
\hline & bring Suspension leg right and left together & $\begin{array}{l}\text { Hang from the horizontal bar, then bring both legs together to the left. } \\
\text { Repeat the same with the right side }\end{array}$ \\
\hline
\end{tabular}

right together (Table 1). Two devices were used for suspension. First TRX $^{\circledR}$ suspension training system (Fitness Anywhere LLC, San Francisco, CA, USA), in which the first 3 exercises were performed by it and second horizontal bar which was attached to metal frame installed in roof and the next 5 exercises were performed by it. Number and time of rest were considered as the first group. The criterion for increasing intensity of exercises was the Borg scale, which according to the problem of participants was remaining up to level 6 for suspension exercises and 5 for core stability exercises. A pilot session was conducted to familiarize the participants with the exercises and test their ability to perform that due to maintaining the safety of participants and to prevent the creation of double pressure. Accordingly, with the feedback we received, we kept the Borg index at a constant number to maintain safety and training intensity. People who were absent for more than thee consecutive sessions or became ill or injured during the study were excluded from the study.

\section{Measurements}

\section{Surface electromyography (sEMG)}

sEMG device of NEGAR company (model 5000Q) was used to record of muscle electrical activity. Electrodes made of silver chloride, signals were recorded with bandwidth of 10 to $500 \mathrm{~Hz}$, sensitivity of $3 \mathrm{mV}$ amplifier and sampling frequency of $1000 \mathrm{~Hz}$. RA, IO, EO and ES muscles were selected to evaluate the activity of core muscles. Then, local body hair was shaved from bottom of the electrode to reduce the noise. Then the place was cleaned with alcohol and the surface electrodes were attached to the skin by electrode adhesives and bandages. The EMG device was connected 
to computer and information was recorded on the computer during the study. Also, all radio and electronic devices in the measuring medium were turned off. All information was collected from the right side of the subjects for uniformity. Placement of the electrode was perpendicular to horizon at $2 \mathrm{~cm}$ outside the umbilicus for RA, at an angle of 45 degrees in the middle of the upper anterior iliac spine to the lowest point of the chest EO, at $2 \mathrm{~cm}$ lower than most prominent part of the upper anterior iliac spine and the upper and inner part of the inguinal ligament for IO [30], and for ES, it was approximately $2 \mathrm{~cm}$ outside third lumbar vertebra and the upper abdominal muscles [31]. The reference electrode was placed on right lateral wrist (styloid process of radus) in all cases.

Maximum voluntary isometric contraction (MVIC) was recorded for each muscle as follows: for RA, subject lay in supine position and bent his hips and knees to a 90-degree position, then tried to flexion his trunk with maximum force against examiner resistance at shoulder level. For right EO, subject lay in the same position and tried to flexion his trunk with left rotation against examiner resistance at shoulder level. For right IO, subject lay in the same position and tried to flexion his trunk with right rotation against of examiner resistance at shoulder level and for ES, the subject lay in prone position and performed maximum isometric force to extend his lumbar against of examiner resistance at posterior surface of shoulder [30]. For each muscle, 3 isometric contractions of $5 \mathrm{~s}$ were performed by the subject with the most effort and 2 min of rest was considered between each attempt. Then, the highest amount of recorded contraction was selected as MVIC.

Electromyographic signal processing was performed using MATLAB software version R2019a. A $50 \mathrm{~Hz}$ filter (to eliminate the effects of city electricity) and a band-pass filter between 10 and $500 \mathrm{~Hz}$ was applied to remove the noise from signal, then a 50-ms moving window was used to calculate the root mean square (RMS).

\section{McGill pain questionnaire}

This questionnaire was used to measure pain and contains a list of 77 factors describing pain that organized into four main classes (sensory perception, affective perception, pain evaluate and miscellaneous) and 20 sub-units. Each contains a minimum of two and a maximum of six words to which pain intensity values are assigned and ranges from 0 (painless) to 78 (severe pain). McGill Pain questionnaire is designed to assess the multidimensional nature of pain experience and demonstrates a valid, reliable measurement tool [32].

\section{Modified schober test (MST)}

MST was used to measure lumbar ROM. Test was performed in such a way that the subject was in a standing position, intersection of the venus cava in lumbar was marked with a marker as a reference line and a line was drawn at a distance of $10 \mathrm{~cm}$ above and $5 \mathrm{~cm}$ below of this point. Then subject was asked to performed lumbar flexion and extension. Measurements were performed using a tape measure. Difference between these points was recorded before and after the performance [33].

\section{Statistical analysis}

SPSS software version 24 was used for data analyze. Shapiro-Wilk test was conducted to evaluate normality of statistical data distribution and Levene test to equality of variance of subjects. Also, paired $t$ test was used for intra-group and analysis of covariance (ANCOVA) and post hoc Bonferroni for intergroup comparison. Statistical significance was set at 0.05 .

\section{Results}

The subjects' information was described in Table 2 using descriptive statistics. Our results were calculated with a 95\% confidence level to confirm the hypothesis. Results of Shapiro-Wilk test confirmed assumption of normal data distribution and Levene test, presumption of variance equality of the subjects' scores in all variables in pre-test. Therefore, according to the pre-conditions, parametric tests were used for analysis.

Results of paired $t$ test showed that there was a significant difference in EMG of all 4 muscles, pain and ROM in groups of suspension ( $p=0.004$ for EMG of ES and $p^{<} 0.001$ for other variables) and core stability exercises ( $p=0.003$ for EMG of ES and $p=0.002$ for $\mathrm{EO}, p=0.003$ for extension ROM and $p^{<} 0.001$ for other variables). However, changes in control group were not significant $(p>0.05)$ (Table 3). Then ANCOVA was used by setting

Table 2 Participants' characteristics

\begin{tabular}{lrcr}
\hline Variable & Suspension group & $\begin{array}{l}\text { Core stability } \\
\text { group }\end{array}$ & Control group \\
\hline Age (year) & $34.25 \pm 8.81$ & $35.00 \pm 10.30$ & $34.4 \pm 6.67$ \\
High $(\mathrm{cm})$ & $178.75 \pm 9.83$ & $181.60 \pm 8.64$ & $178.40 \pm 7.16$ \\
Weight $(\mathrm{kg})$ & $76.16 \pm 2.65$ & $83.10 \pm 15.01$ & $75.50 \pm 3.86$ \\
BMI $\left(\mathrm{kg} / \mathrm{m}^{2}\right)$ & $24.01 \pm 2.70$ & $25.00 \pm 2.27$ & $23.76 \pm 1.45$ \\
\hline
\end{tabular}

$* p<0.05 \mathrm{~cm}$ : centimeter, $\mathrm{Kg}$ kilogeram, $\mathrm{kg} / \mathrm{m}^{2}$ kilogeram/square meters 
Table 3 Intragroup evaluation results with paired $t$ test

\begin{tabular}{llrrrc}
\hline Variable & Groups & Pre & Post & Paired $t$ test & Sig \\
\hline EMG of ES $(\mathrm{mV})$ & Suspension & $0.45 \pm 0.05$ & $0.47 \pm 0.04$ & -3.630 & $0.04^{*}$ \\
& Core & $0.44 \pm 0.05$ & $0.46 \pm 0.04$ & -4.129 & $0.003^{*}$ \\
& Control & $0.44 \pm 0.03$ & $0.44 \pm 0.04$ & 1.152 & 0.279 \\
EMG of EO $(\mathrm{mV})$ & Suspension & $0.47 \pm 0.05$ & $0.62 \pm 0.07$ & -6.246 & $<0.001^{*}$ \\
& Core & $0.44 \pm 0.05$ & $0.54 \pm 0.06$ & -4.400 & $0.002^{*}$ \\
& Control & $0.46 \pm 0.03$ & $0.43 \pm 0.04$ & -0.185 & 0.858 \\
EMG of IO $(\mathrm{mV})$ & Suspension & $0.44 \pm 0 / 03$ & $0.65 \pm 0.09$ & -7.411 & $<0.001^{*}$ \\
& Core & $0.43 \pm 0.05$ & $0.54 \pm 0.09$ & -5.754 & $<0.001^{*}$ \\
& Control & $0.46 \pm 0.04$ & $0.46 \pm 0.04$ & -2.203 & 0.055 \\
EMG of RA $(\mathrm{mV})$ & Suspension & $0.43 \pm 0.05$ & $0.59 \pm 0.02$ & -8.847 & $<0.001^{*}$ \\
& Core & $0.43 \pm 0.03$ & $0.52 \pm 0.06$ & -5.533 & $<0.001^{*}$ \\
& Control & $0.45 \pm 0.03$ & $0.46 \pm 0.04$ & -1.365 & 0.206 \\
Pain & Suspension & $33.66 \pm 9.28$ & $17.08 \pm 6.14$ & 8.269 & $<0.001^{*}$ \\
& Core & $34.10 \pm 8.10$ & $24.70 \pm 6.78$ & 6.363 & $<0.001^{*}$ \\
& Control & $33.10 \pm 5.60$ & $33.00 \pm 5.88$ & 0.142 & 0.891 \\
Flexion ROM $(\mathrm{cm})$ & Suspension & $5.10 \pm 1.20$ & $7.46 \pm 1.43$ & -6.535 & $<0.001^{*}$ \\
& Core & $5.63 \pm 1.00$ & $7.44 \pm 1.23$ & -6.250 & $<0.001^{*}$ \\
& Control & $5.35 \pm 1.11$ & $5.27 \pm 1.11$ & 0.443 & 0.688 \\
Extension ROM $(\mathrm{cm})$ & Suspension & $1.97 \pm 0.43$ & $3.06 \pm 0.79$ & -12.902 & $<0.001^{*}$ \\
& Core & $2.09 \pm 0.44$ & $2.92 \pm 0.53$ & -4.104 & $0.003^{*}$ \\
& Control & $1.96 \pm 0.17$ & $2.17 \pm 0.67$ & -1.148 & 0.280 \\
\hline \multirow{2}{*}{ EM } & & & &
\end{tabular}

${ }^{*} p<0.05 \mathrm{~cm}$ : centimeter, $m V$ millivolt

\begin{tabular}{llrrrrrr}
\hline Variable & & Sum of squares & $d f$ & Mean squares & $F$ & Sig & $\begin{array}{l}\text { Partial eta- } \\
\text { squared }\left(\eta^{2}\right)\end{array}$ \\
\hline EMG of ES (mV) & Contrast & 0.004 & 2 & 0.002 & 8.719 & $0.001 * 0.401$ \\
& Error & 0.006 & 26 & 0.000 & & & \\
EMG of EO (mV) & Contrast & 0.142 & 2 & 0.071 & 18.287 & $<0.001 * 0.584$ \\
& Error & 0.101 & 26 & 0.004 & & & \\
EMG of IO (mV) & Contrast & 0.206 & 2 & 0.103 & 18.234 & $<0.001 * 0.584$ \\
& Error & 0.147 & 26 & 0.006 & & & \\
EMG of RA (mV) & Contrast & 0.097 & 2 & 0.049 & 19.588 & $<0.001 * 0.601$ \\
& Error & 0.064 & 26 & 0.002 & & & \\
Pain & Contrast & 1466.799 & 2 & 733.400 & 46.033 & $<0.001 * 0.780$ \\
& Error & 414.231 & 26 & 15.932 & & & \\
Flexion ROM (cm) & Contrast & 32.720 & 2 & 16.360 & 16.648 & $<0.001 * 0.562$ \\
& Error & 25.550 & 26 & 0.983 & & & \\
Extension ROM (cm) & Contrast & 3.504 & 2 & 1.752 & 8.253 & $0.002 * 0.388$ \\
& Error & 5.519 & 26 & 0.212 & & & \\
\hline
\end{tabular}

${ }^{*} p<0.05 \mathrm{~cm}$ : centimeter, $m V$ millivolt
Table 4 Intergroup evaluation results with ANCOVA pre-test as an intervener factor and results showed that there was a significant difference between the post-test of all variables $(p=0.001$ for EMG of ES, $p=0.002$ for extension ROM and $p<0.001$ for other variables) (Table 4). Therefore, post hoc Bonferroni test was used to evaluate the variables difference between pairwise study groups and results showed that mean of all variables improved significantly compared to control group in suspension ( $p=0.008$ for EMG of ES, $p=0.002$ for extension ROM and $p^{<} 0.001$ for other variables) and core stability groups ( $p=0.007$ for EMG of ES, $p=0.020$ for $\mathrm{EO}, p=0.024$ for IO and $p=0.006$ for RA, $p<0.001$ for pain, $p=0.001$ for flexion ROM and $p=0.022$ for extension ROM). There was a significant difference between 
External oblique

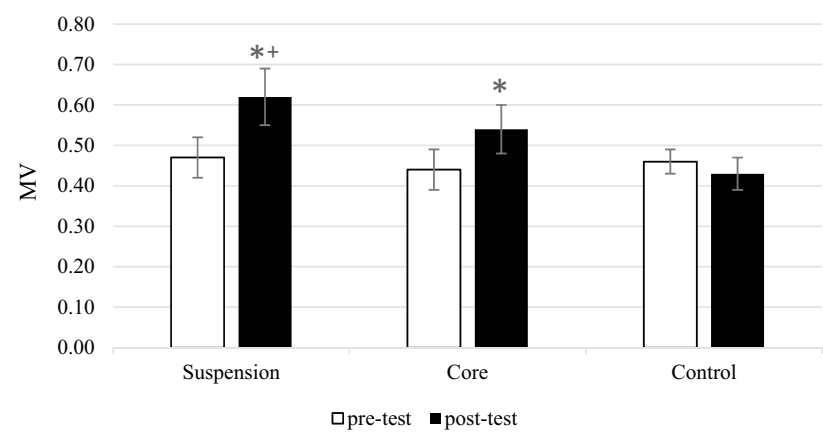

Fig. 1 Changes in EMG of EO muscle in tree groups. *Sign of significant difference compared to control group. ${ }^{+}$Sign of significant difference in suspension group compared to core stability group. post hoc Bonferroni test $\left(p^{<} 0.05\right)$

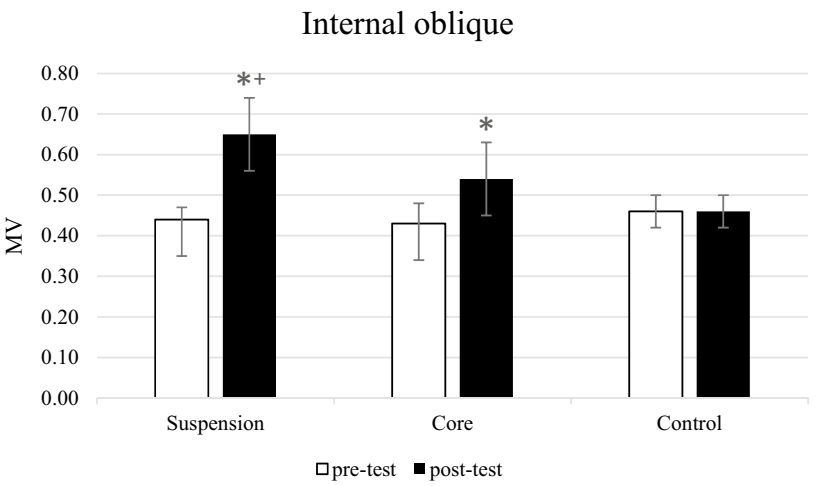

Fig. 2 Changes in EMG of IO muscle in tree groups. *Sign of significant difference compared to control group. ${ }^{+}$Sign of significant difference in suspension group compared to core stability group. post hoc Bonferroni test $\left(p^{<} 0.05\right)$

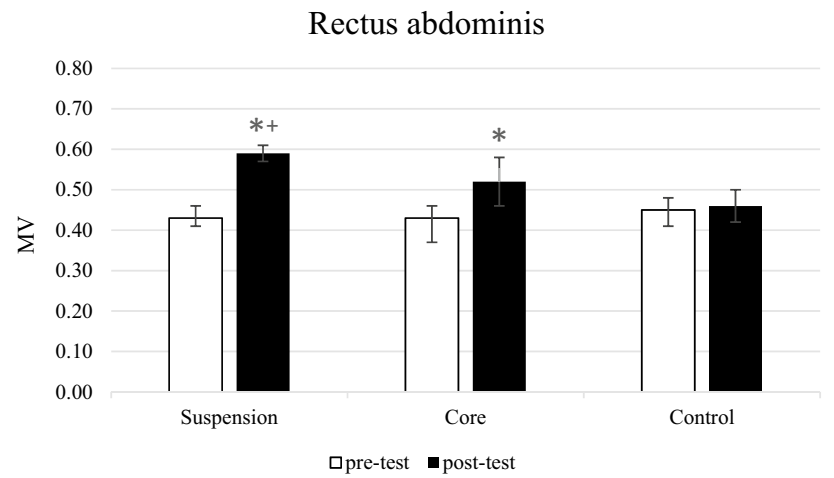

Fig. 3 Changes in EMG of RA muscle in tree groups. * Sign of significant difference compared to control group. ${ }^{+}$Sign of significant difference in suspension group compared to core stability group. post hoc Bonferroni test $\left(p^{<} 0.05\right)$
Pain

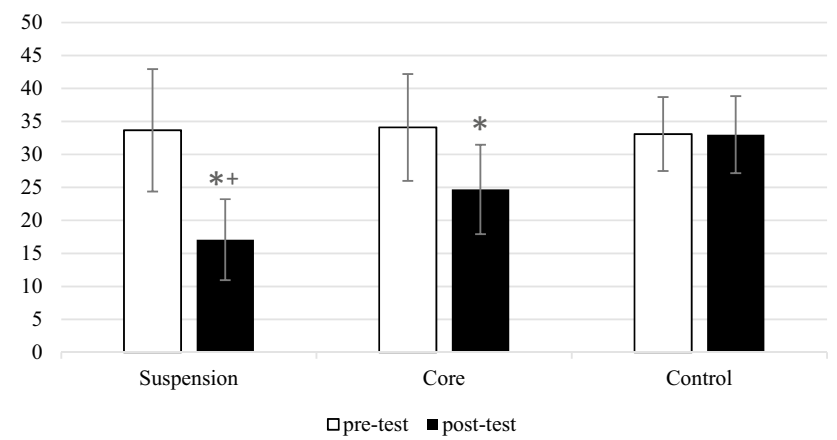

Fig. 4 Changes in amount of pain in tree groups. *Sign of significant difference compared to control group. ${ }^{+}$Sign of significant difference in suspension group compared to core stability group. post hoc Bonferroni test $\left(p^{<} 0.05\right)$

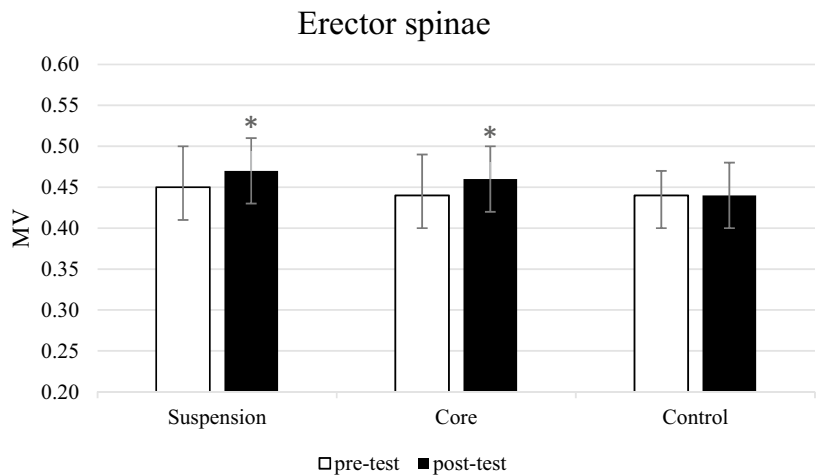

Fig. 5 Changes in EMG of ES muscle in tree groups. *Sign of significant difference compared to control group. post hoc Bonferroni test $\left(p^{<} 0.05\right)$

Flexion ROM

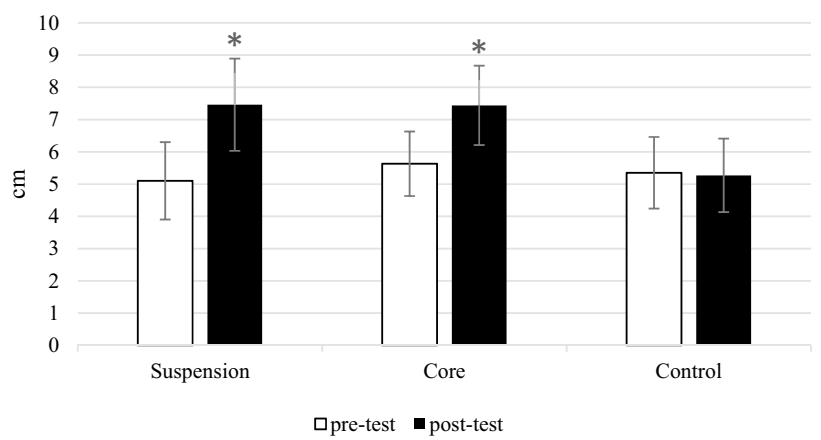

Fig. 6 Changes in flexion ROM in tree groups. *Sign of significant difference compared to control group. post hoc Bonferroni test $\left(p^{<} 0.05\right)$ 


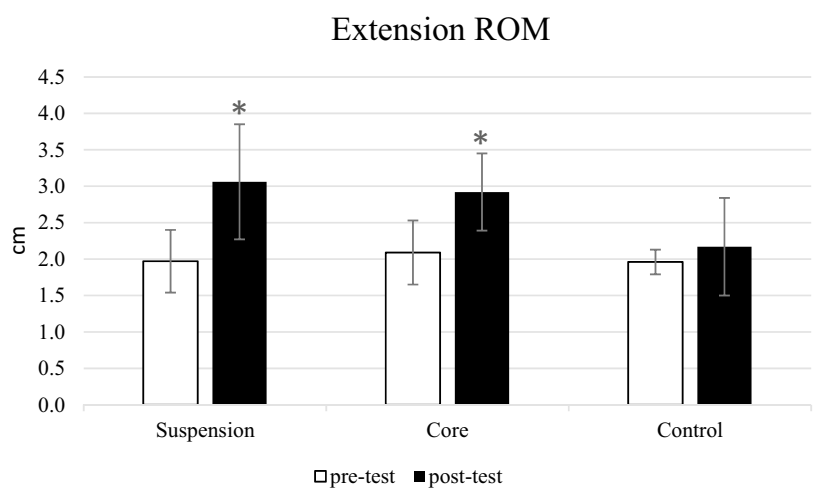

Fig. 7 Changes in Extension ROM in tree groups. *Sign of significant difference compared to control group. post hoc Bonferroni test $\left(p^{<} 0.05\right)$

two groups of suspension and core stability in EMG of 3 muscles ( $p=0.022$ for $\mathrm{EO}, p=0.017$ for $\mathrm{IO}$ and $p=0.030$ for RA) and pain $(p=0.001)$; but this difference was not significant in EMG of ES and flexion and extension ROM $(p>0.05)$ (Figs. 1, 2, 3, 4, 5, 6, 7).

\section{Discussion}

The aim of this study was to compare the effect of two programs of suspension and core stability exercises on some EMG coordinates, pain and ROM of patients with disk herniation. The study's results showed significant improvement in EMG of RA, IO and EO muscles and pain in suspension group compared to core stability group; but there was no significant difference between two groups in EMG of ES and ROM.

In this study, the electrical activity of some abdominal and lumbar muscles during their MVIC was investigated to obtain their activation rate. Findings showed a significant increase in MVIC of all muscles in both exercise groups; but there was no significant difference in the control group. Similar to our findings, some studies observed improvement of muscle activation level after suspension [22, 24] and core stability exercises [34]. Also, Aguilera-Castells et al. (2020) in a systematic review study of 18 studies, reported a very different core muscle activation ranging from moderate to high range [35]. Another finding showed that suspension exercises significantly increased MVIC of RA $(37.20 \%)$, IO $(47.72 \%)$ and EO (31.91\%) compared to core stability exercises (respectively, $20.93 \%, 25.58 \%$ and $22.72 \%$ ); but no significant difference was observed between two types of exercises ES (4.44\% versus $4.54 \%$ ). Similar to our study, Youdas et al. stated that activation of RA, IO and EO in all three models of suspension push-up exercise was significantly higher than standard push-up [23]. Other studies reported a significant improvement in abdominal muscle activity in suspension plank compared to standard plank [36] and suspension push-up compared to standard push-up [37]. However, inconsistent results have also been reported. Aguilera-Castells et al. stated that there is no significant difference in muscle activity between standard and suspension squats [38] and Atkins et al. showed that suspension plank exercise did not result of higher peak amplitude in EO and ES compared to standard plank [25].

A factor that must be considered is that variables, such as intensity, volume and the principle of overload, must be controlled to achieve exercise goals [39]. The principle of overload is essential to challenge the individual in order for occur training adaptation. Resistance in most suspension and unstable exercises is body weight and the intensity of training depends on degree of instability caused by the devices and angles of body [40]. However, in present study, the principle of overload was applied by increasing repetition and duration of muscle contraction. Existence of more load in suspension exercises compared to core stability exercises obtained from Borg index (6 vs 5) was one of the reasons for further progress of suspension exercises group.

On the other hand, in contrast to our result, most previous studies observed higher activation of ES during suspension exercises compared to core stability exercises [16, 21, 36]. Probably our exercises were not focused enough on extensor muscles and may not provide the required level of activation. However, most research has been done on people without LBP, and its important to note that lower levels of activation occur in ES due to high compressive and shear forces at lumbar vertebrae in people with LBP [41].

It has been suggested that muscle dysfunction in patients with chronic LBP may be due to change in one of the neuromuscular control mechanisms affecting trunk stability and movement efficiency, and that lumbar extensor muscles in these cases are weak and highly tired [20]. Also, these patients have a lower percentage of MVIC in trunk muscles when performing movements compared to healthy individuals [21]. The body's stabilization system functions optimally in optimal use of strength, power, neuromuscular control and muscular endurance [42]. Primary role of dynamic stability and segmental control of spine arises from abdominal muscles.Thus, a strong core improves neuromuscular efficiency throughout the motor chain and improves dynamic posture control [43]. Given the above, use of core stability exercises may be effective for LBP patients with movement control disorders.

Suspension exercises may cause more actively involved muscles that were inactivated by LBP and central nervous system to receive more appropriate and effective stimuli from the afferent nerves of deep receptors refering to these muscles [44]. One of possible mechanisms of suspension exercises effect on motor control is that suspension exercises 
have increased control of body position through simultaneous contractions of agonist and antagonist muscles. Therefore, the used exercises probably increase proprioceptive and improve function of muscles around the spine by increasing tonic activity and ability to maintain contraction in the agonist muscle and increase the peripheral inputs [45]. One of the characteristics of instability training is that exercises begin the process of learning new movement patterns and using these exercises may increase muscle recall due to unstable surface [16]. Because the involved muscles must be more activated to prevent unnecessary horizontal and oblique movements [18]. Also, some suspension exercises were performed in hanging position, which was a new combination training method. This hang imposed more weight on the muscles compared to core stability exercises and led to an increase in MVIC of these muscles due to more overload.

Another finding of this study was pain relief in both core stability and suspension exercise groups; but no significant change was observed in control group. According to our results, some studies reported a reduction in pain due to core stability and suspension exercises in people with intervertebral disk herniation [19, 27]. In contrast, Ahmadizadeh et al. reported that core stability exercises combined with self-care education had no effect on pain and functional disability of mothers with LBP who have children with cerebral palsy [46]. Of course, the sex of subjects and this fact that mothers who have children with cerebral palsy have much higher activity and increased pressure on low back can be effective in achieving these different results. Also, our study showed that suspension exercises significantly reduced the pain in people with disk herniation (49.26\%) compared to core stability exercises $(27.57 \%$ ) and both training groups showed a significant improvement compared to control group. Our study was similar to the research of khanzade et al. who reported pain reduction in suspension compared to core stability exercises in end of intervention priod [19].

Lumbar and abdominal muscles become dysfunctional when back pain occurs and because these muscles guide the joint in different patterns of movement and motor function resulting from these different patterns, their damage causes damage to joint function and ultimately occurrence pain and functional disabilities in movements. Therefore, these muscles need retraining. Core stability exercises make the muscles that were inactivated due to LBP more actively involved [42]. These exercises increase strength and coordination of muscles, thereby reduce pain in people with chronic LBP [47].

One of the possible mechanisms of the effect of suspension exercises on pain relief is that these exercises, due to the fact that they are a special form of unstable exercises, can also increase muscle contraction compared to exercises at a more stable level [37]. This unstable nature also causes local and deep muscles to be involved at the same time [48] and it increases neuromuscular control in a closed-chain environment, which improves joint stability and reduces pain by improving the pattern of muscle response and supporting intervertebral joints [49]. Also, some of the suspension exercises we used were performed as a hanging position, which can reduce pain due to traction created on back with help of weight of the lower limbs. It has been reported that cases using gravity-induced passive traction techniques have experienced reduced symptoms and LBP [50]. Traction increases height of the intervertebral disk, increases the intervertebral space and releases nerve root in the intervertebral foramen, which this results reduces of LBP [51].

Another finding of this study was a significant increase in ROM in suspension and core stability exercise groups; but no significant change was observed in control group. Some studies reported similar result in people with chronic LBP $[14,27]$. On the other hand, in the study of Kuligowski et al. (2021), core stability exercises reduced lumbar ROM in people with disk herniationm [26]. Difference in severity of disk herniation of the subjects and period of core stability exercises used in this study (four weeks) could be the reasons why this research is different from our research. Our study also showed that there is no significant difference between effect of two suspension and core stability exercises program on lumbar ROM of people with disk herniation; but both exercise groups significantly increased the range of flexion and extension compared to control group.

Pain and dysfunction of vertebrae and intervertebral disks reduce ROM of lumbar spine [10]. It is also believed that motion in patients with LBP causes pain due to process of chronic pain followed by muscle spasm and decreased flexibility in musculoskeletal system. As a result, these patients refrain from moving to prevent recurrence of pain, which leads to a reduction in ROM of the lumbar spine [52]. It has been stated that muscle imbalance leads to pelvic tilt changes and reduced ROM in spinal flexion [53]. Core stability exercises program improves function of musculoskeletal system, which leads to optimal movement of lumbar-pelvic joints along functional chain, acceleration or reduction of proper acceleration, proper muscle balance and functional strength [42] and reducing pain caused by these exercises is also effective in improving ROM [14]. On the other hand, suspension exercises increase neuromuscular coordination and relieve unnecessary pressures due to creation of an unstable environment and by increasing muscle activation, improve ROM of the joints [27]. It has been stated that loads applied in unstable conditions may be a sufficient stimulus to produce adaptation and increase ROM [54]. Furthermore, there was no significant difference between suspension and core stability exercises in increasing lumbar ROM, which could be due to the same movement pattern used in our exercises and increasing muscle activation alone was not a 
sufficient stimulus to improve ROM compared to core stability exercises.

\section{Limitations}

The gender of subjects was the main limitation of this study, along with reduction in number of people in the subgroups, which was caused by the pandemic of COVID-19 and the withdrawal of a number of volunteers. Other limitations of this study were mental state of the subjects and their motivation to perform exercises. Due to the mentioned factors, it is recommended to perform this study in women and on more subjects. It is also useful to examine other factors involved in LBP, including when to start activation and fatigue of the lumbar muscles, before and after exercises.

\section{Conclusion}

Our funding showed that both suspension and core stability exercises improved core muscle activation, reduced pain and increased lumbar ROM in patients with lumbar disk herniation. One of the interesting results in present study was more prominent role of suspension exercises in muscle activation and reducing pain compared to core stability exercises.

Acknowledgements We appreciate the respected Dr. Navid Hosseinzade (Ph.D of physical medicine and rehabilitation), Dr. Shervin Ghadarjani (neurosurgeon), personnel of Razi Medical Laboratory and all the dear participants who helped us with great patience in this research under the title of a doctoral thesis.

Author contributions All authors contributed to the study conception and design. Material preparation, data collection and analysis were performed by Yasser Mohebbi Rad, Mohammad Reza Fadaei Chafy and Alireza Elmyeh. The first draft of the manuscript was written by Yasser Mohebbi Rad and all authors commented on previous versions of the manuscript. All authors read and approved the final manuscript.

Funding The authors did not receive support from any organization for the submitted work. No funding was received to assist with the preparation of this manuscript. No funding was received for conducting this study and no funds, grants, or other support was received.

Data Availability The datasets generated during or analyzed during the current study are available from the corresponding author on reasonable request.

\section{Declarations}

Conflict of interest The authors have no conflicts of interest to declare that are relevant to the content of this article.

Ethical approval All procedures performed in studies involving human participants were in accordance with the ethical standards of the institutional committee and with the 1964 Helsinki Declaration and its later amendments or comparable ethical standards. The study was approved by the Bioethics Committee of Islamic Azad University-Rasht Branch
(No: IR.IAU.RASHT.REC.1399.019). This clinical trial registered in Iranian Registry of Clinical Trials (IRCT): IRCT20191016045136N1

Informed consent Informed consent was obtained from all individual participants included in the study.

Consent to participate Patients signed informed consent regarding publishing their data and photographs.

\section{References}

1. Kreiner DS, Hwang SW, Easa JE, Resnick DK, Baisden JL, Bess S et al (2014) An evidence-based clinical guideline for the diagnosis and treatment of lumbar disc herniation with radiculopathy. Spine J 14(1):180-191

2. Tarulli AW, Raynor EM (2007) Lumbosacral radiculopathy. Neurol Clin 25(2):387-405

3. Jordon J, Konstantinou K, O'Dowd J. (2009) Herniated lumbar disc. BMJ Clin Evid 2009.

4. Cho KH, Beom JW, Lee TS, Lim JH, Lee TH, Yuk JH (2014) Trunk muscles strength as a risk factor for nonspecific low back pain: a pilot study. Ann Rehabil Med 38(2):234

5. Yahia A, Jribi S, Ghroubi S, Elleuch M, Baklouti S, Elleuch MH (2011) Evaluation of the posture and muscular strength of the trunk and inferior members of patients with chronic lumbar pain. Jt Bone Spine 78(3):291-297

6. Van Middelkoop M, Rubinstein SM, Verhagen AP, Ostelo RW, Koes BW, van Tulder MW (2010) Exercise therapy for chronic nonspecific low-back pain. Best Pract Res Clin Rheumatol 24(2):193-204

7. Vasseljen O, Fladmark AM (2010) Abdominal muscle contraction thickness and function after specific and general exercises: a randomized controlled trial in chronic low back pain patients. Man Ther 15(5):482-489

8. Arvanitidis M, Bikinis N, Petrakis S, Gkioka A, Tsimpolis D, Falla D et al (2021) Spatial distribution of lumbar erector spinae muscle activity in individuals with and without chronic low back pain during a dynamic isokinetic fatiguing task. Clin Biomech 81:105-214

9. Larsen LH, Hirata RP, Graven-Nielsen T (2018) Experimental low Back pain decreased trunk muscle activity in currently asymptomatic recurrent low back pain patients during step tasks. J Pain 19(5):542-551

10. Balagué F, Mannion AF, Pellisé F, Cedraschi C (2012) Nonspecific low back pain. The Lancet 379(9814):482-491

11. Frizziero A, Pellizzon G, Vittadini F, Bigliardi D, Costantino C (2021) Efficacy of core stability in non-specific chronic low back pain. J Funct Morphol Kinesiol 6(2)

12. Kibler WB, Press J, Sciascia A (2006) The role of core stability in athletic function. Sports Med 36(3):189-198

13. Sipaviciene S, Kliziene I (2020) Effect of different exercise programs on non-specific chronic low back pain and disability in people who perform sedentary work. Clin Biomech 73:17-27

14. Bhadauria EA, Gurudut P (2017) Comparative effectiveness of lumbar stabilization, dynamic strengthening, and Pilates on chronic low back pain: randomized clinical trial. J Exerc Rehabil 13(4):477

15. Okubo Y, Kaneoka K, Imai A, Shiina I, Tatsumura M, Izumi $S$ et al (2010) Electromyographic analysis of transversus abdominis and lumbar multifidus using wire electrodes during lumbar stabilization exercises. J Orthop Sports Phys Ther 40(11):743-750 
16. Harris S, Ruffin E, Brewer W, Ortiz A (2017) Muscle activation patterns during suspension training exercises. Int J Sports Phys Ther 12(1):42

17. Behm DG, Anderson KG (2006) The role of instability with resistance training. J Strength Cond Res 20(3):716

18. Anderson GS, Gaetz M, Holzmann M, Twist P (2013) Comparison of EMG activity during stable and unstable push-up protocols. Eur J Sport Sci 13(1):42-48

19. Khanzadeh R, Mahdavinejad R, Borhani A (2020) The effect of suspension and conventional core stability exercises on characteristics of intervertebral disc and chronic pain in office staff due to lumbar herniated disc. Arch Bone Jt Surg 8(3):445-453

20. Cho S-H, Park S-Y (2019) Immediate effects of isometric trunk stabilization exercises with suspension device on flexion extension ratio and strength in chronic low back pain patientss. J Back Musculoskelet Rehabil 32(3):431-436

21. Kang H, Jung J, Yu J (2012) Comparison of trunk muscle activity during bridging exercises using a sling in patients with low back pain. J Sports Sci Med 11(3):510

22. Lee S-Y, Park S-Y. (2021) Comparison among low intensity bridge exercises using suspension devices based on muscle activity and subjective difficulty. J Back Musculoskelet Rehabil.

23. Youdas JW, Baartman HE, Gahlon BJ, Kohnen TJ, Sparling RJ, Hollman JH (2020) Recruitment of shoulder prime movers and torso stabilizers during push-up exercises using a suspension training system. J Sport Rehabil 29(7):993-1000

24. Frison VB, Lanferdini FJ, Geremia JM, de Oliveira CB, Radaelli $R$, Netto CA et al (2019) Effect of corporal suspension and pendulum exercises on neuromuscular properties and functionality in patients with medullar thoracic injury. Clin Biomech 63:214-220

25. Atkins SJ, Bentley I, Brooks D, Burrows MP, Hurst HT, Sinclair JK (2015) Electromyographic response of global abdominal stabilizers in response to stable-and unstable-base isometric exercise. J Strength Cond Res 29(6):1609-1615

26. Kuligowski T, Cieślik B, Kuciel N, Dębiec-Bąk A, Skrzek A (2021) Effect of core stabilizing training on young individuals presenting different stages of degenerative disc disease-preliminary report. Int J Environ Res Public Health 18(7):3499

27. Ko K-J, Ha G-C, Yook Y-S, Kang S-J (2018) Effects of 12-week lumbar stabilization exercise and sling exercise on lumbosacral region angle, lumbar muscle strength, and pain scale of patients with chronic low back pain. J Phys Ther Sci 30(1):18-22

28. Acar Y, Ilçin N, Gürpinar B, Can G (2019) Core stability and balance in patients with ankylosing spondylitis. Rheumatol Int 39(8):1389-1396

29. Nabavi N, Bandpei MAM, Mosallanezhad Z, Rahgozar M, Jaberzadeh S (2018) The effect of 2 different exercise programs on pain intensity and muscle dimensions in patients with chronic low back pain: a randomized controlled trial. J Manipulative Physiol Ther 41(2):102-110

30. Ng JKF, Richardson CA, Parnianpour M, Kippers V (2002) EMG activity of trunk muscles and torque output during isometric axial rotation exertion: a comparison between back pain patients and matched controls. J Orthop Res 20(1):112-121

31. Escamilla RF, Lewis C, Bell D, Bramblet G, Daffron J, Lambert $\mathrm{S}$ et al (2010) Core muscle activation during Swiss ball and traditional abdominal exercises. J Orthop Sports Phys Ther 40(5):265-276

32. Dworkin RH, Turk DC, Revicki DA, Harding G, Coyne KS, Peirce-Sandner S et al (2009) Development and initial validation of an expanded and revised version of the Short-form McGill Pain Questionnaire (SF-MPQ-2). Pain 144(1-2):35-42

33. Robinson HS, Mengshoel AM (2014) Assessments of lumbar flexion range of motion: intertester reliability and concurrent validity of 2 commonly used clinical tests. Spine 39(4):270-275
34. Ramos LAV, Callegari B, França FJR, Magalhães MO, Burke TN, Carvalho APdMC et al (2018) Comparison between transcutaneous electrical nerve stimulation and stabilization exercises in fatigue and transversus abdominis activation in patients with lumbar disk herniation: a randomized study. J Manipulative Physiol Ther 41(4):323-331

35. Aguilera-Castells J, Buscà B, Fort-Vanmeerhaeghe A, Montalvo AM, Peña J (2020) Muscle activation in suspension training: a systematic review. Sports Biomech 19(1):55-75

36. Calatayud J, Casaña J, Martín F, Jakobsen MD, Colado JC, Andersen LL (2017) Progression of core stability exercises based on the extent of muscle activity. Am J Phys Med Rehabil 96(10):694-699

37. Beach TA, Howarth SJ, Callaghan JP (2008) Muscular contribution to low-back loading and stiffness during standard and suspended push-ups. Hum Mov Sci 27(3):457-472

38. Aguilera-Castells J, Buscà B, Morales J, Solana-Tramunt M, FortVanmeerhaeghe A, Rey-Abella F, et al. (2019) Muscle activity of Bulgarian squat. Effects of additional vibration, suspension and unstable surface. PloS One 14(8).

39. Wernbom M, Augustsson J, Thomeé R (2007) The influence of frequency, intensity, volume and mode of strength training on whole muscle cross-sectional area in humans. Sports Med 37(3):225-264

40. Giancotti GF, Fusco A, Varalda C, Capelli G, Cortis C (2021) Evaluation of training load during suspension exercise. J Strength Cond Res 35(8):2151-2157

41. Behm D, Colado JC (2012) The effectiveness of resistance training using unstable surfaces and devices for rehabilitation. Int $\mathrm{J}$ Sports Phys Ther 7(2):226

42. Wirth K, Hartmann H, Mickel C, Szilvas E, Keiner M, Sander A (2017) Core stability in athletes: a critical analysis of current guidelines. Sports Med 47(3):401-414

43. Chan EWM, Hamid MSA, Nadzalan AM, Hafiz E (2020) Abdominal muscle activation: an EMG study of the Sahrmann five-level core stability test. Hong Kong Physiother J 40(02):89-97

44. Brumagne S, Cordo P, Verschueren S (2004) Proprioceptive weighting changes in persons with low back pain and elderly persons during upright standing. Neurosci Lett 366(1):63-66

45. Cugliari G, Boccia G (2017) Core muscle activation in suspension training exercises. J Hum Kinet 56(1):61-71

46. Ahmadizadeh Z, Ehsani F, Samaei SA, Mirmohammadkhani M (2020) The effect of stabilization exercises along with self-care training on transverse abdominal activity, pain, and disability in mothers with low back pain having children with cerebral palsy: a randomized controlled trial. Am J Phys Med Rehabil 99(2):156-160

47. Letafatkar A, Nazarzadeh M, Hadadnezhad M, Farivar N (2017) The efficacy of a HUBER exercise system mediated sensorimotor training protocol on proprioceptive system, lumbar movement control and quality of life in patients with chronic non-specific low back pain. J Back Musculoskelet Rehabil 30(4):767-778

48. Lee J-S, Yang S-H, Koog Y-H, Jun H-J, Kim S-H, Kim K-J (2014) Effectiveness of sling exercise for chronic low back pain: a systematic review. J Phys Ther Sci 26(8):1301-1306

49. Marshall PW, Murphy BA (2006) Increased deltoid and abdominal muscle activity during Swiss ball bench press. J Strength Cond Res 20(4):745-750

50. Chou R, Huffman LH (2007) Nonpharmacologic therapies for acute and chronic low back pain: a review of the evidence for an American Pain Society/American College of Physicians clinical practice guideline. Ann Intern Med 147(7):492-504

51. Cannon J, Emond D, McGill SM (2016) Evidence on the ability of a pneumatic decompression belt to restore spinal height following an acute bout of exercise. J Manipulative Physiol Ther 39(4):304-310 
52. van Dieën JH, Selen LP, Cholewicki J (2003) Trunk muscle activation in low-back pain patients, an analysis of the literature. J Electromyogr Kinesiol 13(4):333-351

53. Retailleau M, Colloud F (2020) New insights into lumbar flexion tests based on inverse and direct kinematic musculoskeletal modeling. J Biomech 105:109782
54. Drinkwater EJ, Pritchett EJ, Behm DG (2007) Effect of instability and resistance on unintentional squat-lifting kinetics. Int J Sports Physiol Perform 2(4):400-413

Publisher's Note Springer Nature remains neutral with regard to jurisdictional claims in published maps and institutional affiliations. 